\title{
Levanta-te e anda! Duas palavras sobre o passado, o presente e o futuro dos deficientes na África
}

\author{
João Vicente Ganzarolli de Oliveira* \\ A vida é uma tentativa de ficar em pé. \\ Carmelino Souza Vieira
}

\section{Resumo}

Por que há tantas crianças cegas em Ruanda? Por que a deficiência é ainda hoje um flagelo e um estigma em terras africanas? Qual será o legado desta geração para o deficiente do ano 2050, quando a população da Terra deverá atingir a cifra de dez bilhôes? Este artigo concentra-se na atuação de missionários europeus e do seu esforço para combater a deficiência na África. Deixando de lado os clichês e a correção política, é-se obrigado a admitir que a presença ocidental na África tem trazido benefícios vitais não só para os deficientes, mas para a população africana em geral.

Palavras-chave: África; Deficiência; Missionários.

* Professor doutor da Universidade Federal do Rio de Janeiro. Rio de Janeiro, Rio de Janeiro, Brasil. 


\section{Stand up and walk! Brief remarks about the past, the present, and the future of the handicapped Africas}

\section{Abstract}

Why are so many blind children in Ruanda? Why is physical impairment still a scourge and a stigma in African lands? What is going to be the legacy of this generation for the handicapped people of year 2050, when human population on Earth is estimated to be of 10 billion? This article focuses the effort of European missionaries to fight physical impairment in Africa. Setting aside the anti-European clichés and political correctness, one has to admit that Western performance in Africa has brought vital benefits for the handicapped as well as for African people in general.

Keywords: Africa; Impairment; Missionaries.

Quem conta é o missionário catalão Xavier Morell i Sauch, que passou vários anos em Ruanda. O filho de um pigmeu morrera atropelado. Após receber certa quantia como indenização, o pai decidiu colocar outro de seus filhos na estrada para que este também fosse atropelado e, assim, lhe rendesse uma nova quantia: "a aquell bon home no se li acudi altra cosa que exposar un altre dels seus fills a la circulació rodada per a veure si aixi l'atropellaven, podia cobrar més diners?' (SAUCH, 2007). Isso que lemos no livro auto-biográfico El sentit d'una vida (O sentido de uma vida) está longe de ser um fato isolado; muitos casos parecidos permitem concluir que se trata de um costume próprio da África. É comum que a vida de um homem valha pouco no continente que viu o ser humano nascer. Menos ainda tende a ser o valor da vida dos deficientes físicos e dos pigmeus, que para muitos africanos nem sequer fazem parte da espécie humana.

Nenhuma sociedade é indiferente à deficiência que atinge seus membros; poderá aceitá-la ou rechaçá-la, mas nunca ignorá-la. A segregação do deficiente não tem nenhum fundamento moral e nem biológico: depende do arbítrio cultural, e por isso seu território e sua abrangência são imprecisos. Entre os budistas existe a prerrogativa de melhorar a sorte dos mais vulneráveis (é como se tivessem lido Nietzsche e Rousseau, para adotar justamente o contrário do que eles recomendam nesses casos [cf. NIETZSCHE, 1952; ROUSSEAU, 1979]), grupo no qual se incluem os cegos e demais deficientes. No começo da Idade Média, São Gregório Magno escreveu sobre um italiano de nome Sérvulo, a quem a doença "havia reduzido a um estado lastimável: passada a sua juventude, ficou paralítico de todos os seus membros" (JAUD, 1933 , p. 555). Havendo aceito a provação, Sérvulo dedicava-se a meditar sobre os sofrimentos de Cristo, e isso "de tal maneira que não se queixava jamais" (apud Ibidem). "Conhecido por todos os moradores de Roma" (apud Ibidem), teve amigos e continua a ser admirado em nossa época. Fala-se aqui de costumes e atitudes que escapam das regras gerais; o comum, ao longo da história da humanidade, tem sido a discriminação do deficiente. $\mathrm{O}$ assunto já comparece num dos escritos mais antigos 
que chegaram a nós. O Livro da sabedoria, atribuído ao egípcio Amenemope, traz o seguinte conselho: "não rias do cego, não ridicularizes o anão e não faças mal ao paralítico" (apud GRIMBERG, 1965). Se tais procedimentos mereceram a atenção do sábio, certamente é porque eles ocorriam com frequência no Egito dos faraós.

Em muitos países africanos da atualidade, faltam carrinhos de bebê - e ainda que houvesse, seria difícil comprá-los. As mães costumam levar os filhos pequenos amarrados nas costas, deixando-os, assim, à mercê dos mosquitos, que atacam os olhos, trazendo doenças causadoras da cegueira ou até mesmo destruindo diretamente a córnea. Com frequência, a cegueira decorre de problemas congênitos, da falta de higiene e da má nutrição. Isso responde à pergunta feita a si mesmo pelo padre Xavier Morell i Sauch, ao deparar com tantas crianças cegas em Ruanda: "Per què tants nens cecs?" (2007, p. 161). Estamos diante de um quadro tipicamente africano e que mudou pouquíssimo durante milênios. No Egito faraônico, as doenças oculares eram tidas como "um verdadeiro flagelo nacional"; as causas eram as mesmas atuantes hoje em dia, notadamente a falta de higiene e de proteção contra os mosquitos. Se atualmente a eliminação dos deficientes não é mais uma prática generalizada em solo africano, isso se deve aos esforços de médicos e missionários europeus: David Livingstone, Albert Schweitzer e tantos outros que fizeram da África a sua pátria. Um pouco menos conhecido do que o inglês Livingstone (1813-1873), o alemão Schweitzer (1875-1965), médico extraordinário, encontrou tempo para brilhar como protetor dos africanos (notadamente gaboneses), teólogo, filósofo, músico e escritor. Foi laureado meritoriamente com o Prêmio Nobel da Paz em 1952. Há quase cem anos, por ocasião do fim da Primeira Guerra Mundial, Albert Schweitzer declarava: "Começaremos novamente. Devemos dirigir nosso olhar para a humanidade".

Não deve ser perdido de vista que muitos desses missionários foram mártires; que pensemos no catalão medieval Raimundo Lúlio, apedrejado por muçulmanos argelinos, e no francês Charles de Foucauld, morto a tiros por beduínos islamitas da mesma Argélia. Seu assassinato, em 1916, pode ser visto como ponto de convergência de incontáveis outros, cometidos por muçulmanos contra cristáos, desde a islamização do Oriente Médio e do norte da África, ocorrida entre os séculos VII e VIII. Foi prelúdio também para as grandes matanças do século XX (e.g., o genocídio dos armênios, cometido pelos turcos) e do século XXI. Apenas em 2012, mais de cem mil cristãos foram assassinados em países islâmicos, genocídio que não teve impacto na mídia e que muitas autoridades eclesiásticas parecem ignorar (cf. Reinaldo Azevedo. "Os mortos do Egito sem direito nem mesmo à notícia. Ou: Islamofilia da imprensa ocidental esconde os cadáveres dos cristáos". Esperemos que o assassinato recente do padre jesuíta holandês Frans van der Lugt faça com que o Vaticano e a mídia em grande escala finalmente despertem para o desamparo dos cristáos em meio ao fogo cruzado das facçóes islamitas que brigam pelo poder durante esta longa "primavera árabe".

Defensor incansável dos deficientes, dos escravos e dos desfavorecidos em geral, Charles de Foucauld acreditava que todos os homens eram livres para escolher o seu próprio destino. No Magreb, que escolheu como pátria e que se tornou seu 
túmulo, essa crença incomodou demais (cf. CARROUGES, 1954). Mártir da própria fama e da banalização imposta pela mídia, a ex-princesa Diana (1961-1997) precisa ser lembrada por seu esforço pela desativação das minas em solo africano, bem como pelo fim da sua indústria de fabricação. Decepcionante, o filme Diana (2013), de Oliver Hirschbiegel, concentra-se em aspectos pessoais e escandalosos da vida de Lady Di. A interpretação caricatural de Naomi Watts transmite a idéia de uma adolescente irresponsável. Da atuação corajosa e pioneira da inglesa Diana Frances Spencer em defesa das vítimas de amputaçóes causadas pelas minas, pouquíssimo se fala no filme. Peter Bradshaw, crítico do Guardian, considerou o filme uma "segunda morte horrível" para Diana.

Não foi a primeira e nem a última vez em que a mídia pôs uma lente de aumento sobre as fraquezas pessoais - quem não as tem? - de uma grande personalidade britânica, obscurecendo suas muitas virtudes e massacrando-a psicologicamente diante de um público sempre ávido de atirar a primeira pedra. Em 1963, jornais de todo o mundo dedicaram letras garrafais para denunciar a infidelidade conjugal do então ministro inglês John Profumo, veterano da Segunda Guerra, que foi obrigado a demitir-se e desistir da vida pública. A mídia só desviou o foco quando um alvo mais atrativo surgiu: os Beatles, reestruturados após a estadia em Hamburgo, voltavam ao solo inglês e aconteciam para o resto do mundo. Profumo foi esquecido. Por ocasião da sua morte, em 2006, quase nada se falou e escreveu que, após o vilipêndio e a humilhaçáo sofridos em 1963, Profumo passou a trabalhar como voluntário do Toynbee Hall, lavando banheiros e aproveitando o pouco de prestígio que lhe restara para arrecadar fundos caritativos, promovendo com eles a integração social de ingleses e estrangeiros pobres em solo britânico. A esposa o apoiou, a rainha da Inglaterra homenageou-o em 1975 e a ex-primeira ministra Margareth Thatcher - ela mesma vilipendiada num filme recente (The Iron Lady, 2011) - nunca deixou de admirá-lo. Para a maior parte da mídia, Profumo morrera em 1963.

Há cerca de um milhão e meio de anos, o homem saiu do continente africano pela primeira vez e começou a se espalhar pela Terra. Daí a expressão "out of Africa", de que a antropologia se serve para explicar tal fenômeno. ${ }^{1}$ Esses primeiros grandes viajantes levaram consigo as conquistas e os estigmas acumulados durante mais de cinco milhôes de anos, haja vista que nossos ancestrais mais antigos surgiram há cerca de sete milhôes de anos. Entre os estigmas já constava, possivelmente, a segregação dos deficientes. Convençóes e leis protetoras dos interesses dos deficientes existem na África atual. Muitas vezes, contudo, é difícil transformar a teoria em prática; as barreiras partem das próprias sociedades africanas, que tendem a discriminar os deficientes nos mais diversos setores da vida comunitária. Ainda hoje muitos africanos vêem a deficiência como um castigo para a família, pretexto que serve de "justificativa" para a rejeição. Esse polígono de problemas é integrado por diferentes modalidades de superstição, dentre elas a de que os albinos seriam fantasmas dotados de poderes especiais. Caçados por feiticeiros e traficantes, vários albinos foram mortos nos últimos anos na Tanzânia e no Burundi, onde partes dos seus corpos têm sido utilizadas para a fabricação de poçôes e talismãs. Sabendo-se que o preço a pagar por cada cadáver pode chegar até a 400 mil dólares, tem-se uma ideia da dimensão dos inte- 
resses envolvidos; estamos falando de terras onde a miséria, o parasitismo masculino (sim, pois continua em pleno vigor a crendice tipicamente africana de que "trabalho é algo para escravos e mulheres"), a crueldade e a indiferença para com o próximo são moeda corrente (cf. ZAPPA, 2010). Quanto mais pobre for uma localidade da África, mais corriqueira é a cena da mulher curvada, carregando uma carga pesadíssima sobre as costas, enquanto os homens se espreguiçam encostados nas árvores e à beira dos sobrados. Ao menos foi o que constatei durante as visitas que fiz a países africanos, ao longo de uma década: entre 2001 e 2011.

Uma das “justificativas" para a caça aos albinos está no preconceito que associa o albinismo ao retardo mental. Para muitos africanos, o albino vivo é socialmente inútil; morto, vale bem mais. Jeff Luande, médico do hospital oncológico de Dar es Salaam, na Tanzânia, comenta com propriedade a relação existente entre o albinismo e a baixa visão. Diz que a simples boa vontade e o bom senso por parte dos professores poderiam minimizar significativamente os obstáculos que o albino costuma enfrentar no processo de aprendizado: "Nas escolas públicas, muitos professores não sabem que, trazendo para as primeiras carteiras os albinos, quase sempre considerados estúpidos, dar-lhes-iam a oportunidade de ler o que está no quadro negro e, consequentemente, aumentariam suas chances de sucesso escolar" (ZAPPA, 2010, p. 20-22).

São muitas as dificuldades a vencer, mas, para vencê-las, é preciso começar, ainda que de forma modesta. É como pensam os fundadores de uma associação de deficientes em Freetown, na Serra Leoa, que tem esta frase como lema: "A deficiência não é incapacidade". Atingida pela poliomielite na infância, Tahara Haïdara nasceu no Mali, país marcado pela pobreza e pelos muitos conflitos internos. Venceu nas três frentes que a África lhe impôs: a da pobreza, a da deficiência e a de ser mulher. Casada, máe de quatro filhos e dona de um hotel na cidade de Timbuctu, Tahara também é a fundadora da Associação de mulheres deficientes de Timbuctu, para a qual ela obteve auxílio de entidades filantrópicas da Europa. Juntamente com suas colegas, ela produz sabonetes e peças artesanais diversas. Isso condiz com os ensinamentos do economista asiático Muhammad Yunus, o "banqueiro dos pobres", segundo o qual, em países pobres, as empresas dirigidas por mulheres costumam funcionar melhor (SPIEGEL, 2009).

"Sobreviver ainda não é viver", lê-se num folheto publicado pela associação internacional Caritas, que divulga a sua atuação em comunidades de artesãos na Índia, na Etiópia, no México, na Bolívia e noutros países do Terceiro Mundo. É nesse contexto que se enquadra a iniciativa de Patrick Meredith e Henri Asse (ambos médicos, um europeu e o outro africano): a criação de um instituto de cirurgia plástica na Costa do Marfim, país em que a lepra constitui problema gravíssimo. Para os dois médicos associados, o objetivo principal do projeto (uma realidade desde o ano 2000, a Fondation Meredith) era restituir às vítimas da lepra, mediante cirurgia plástica, condiçóes físicas que lhes permitiriam o ingresso na vida profissional em seu país (TISSOT, 2001). Em praticamente toda a África, ingressar na vida profissional constitui, em si, um grande desafio. Os bons empregos são poucos e a concorrência é enorme - situação que desfavorece ainda mais o deficiente. 
Sabe-se que, na África, "o inseto é mais perigoso do que a fera, e o micróbio mais ainda do que o inseto" (BERTAUX, 1994, p. 133 et passim). Ferimentos simples muitas vezes evoluem para um quadro de gangrena, o que costuma resultar em amputaçóes: prefere-se o curandeiro ao antibiótico. É o célebre dilema entre a medicina tribal - representativa de uma tradição milenar - e a ocidental, não raro vista com antipatia. Ora, de que vale alimentar rancores e revanchismos contra a cultura ocidental, indo ao extremo oposto do servilismo de outrora, rejeitando in toto o que quer que venha do Ocidente? A escravidão e a discriminação étnica existem na África desde muito antes da chegada dos primeiros colonizadores europeus, bem como das primeiras caravanas de maometanos que percorriam o sahel africano para capturar escravos. Ao longo dos três séculos em que tomaram parte no tráfico negreiro (sempre capitaneado por muçulmanos, e isso desde o século VIII), o número de africanos levados como escravos para o Oriente islâmico foi muito superior ao dos que vieram para as colônias européias na América (cf. PENNA, 1997). Entre 1500 e 1800, houve pelo menos um milhão de escravos brancos na África (cf. NARLOCH, 2011). Não só na África, mas em todo o mundo atual, os principais paladinos do combate à escravidáo, ao tráfico humano e à discriminaçáo étnica pertencem à cultura judaico-cristá; que se pense nos norte-americanos Don Brewster e Mira Sorvino, e nos filipinos Manny Pacquiao e Cecilia Flores Oebanda. Entre as exceçôes estáo os abolicionistas islâmicos Biran Dah Abeid e Birane Abdoul Wone. Homenageado e condecorado no Ocidente, Biran Dah Abeid tornou-se persona non grata na Mauritânia; seu colega Birane Abdoul Wone foi condenado à cadeia.

Desde o início da vida na Terra, há cerca de quatro bilhôes de anos, incontáveis espécies existiram e se extinguiram. Atualmente, uma única espécie, a nossa, tem domínio sobre todo o planeta. Calcula-se que seremos dez bilhóes por volta do ano 2050 (cf. EMMOTT, 2013). Não se deve esquecer desta lei inexorável da natureza: todo aumento exagerado de uma população converge para a sua extinção em massa: "Doch wie bei jeder Massenvermehrung, so folgt auch hier das Massensterben unerbitlich nach" (DRÖSCHER, 1987). É o caso de pensarmos seriamente nisso e nos perguntarmos: como ficará a situação do deficiente num mundo super-povoado (como já é o nosso), em que o consumo tornou-se um vício e a comunicação uma prática em declínio? Neste mundo em que as conversas se resumem cada vez mais a "apertar botôes", já não conversamos uns com os outros. Lembro-me de longas viagens que fiz, entre 1980 e 2000, pela América Latina, a Europa, o Oriente Próximo e a Ásia. Era quase impossível cruzar os Andes num Morales Moralitos, viajar de trem pelo norte da Itália, visitar as ruínas de Palmira (vítima arqueológica da "primavera árabe") ou passear pelo centro de Katmandu sem conhecer pessoas interessantes; era fácil fazer amigos. Com a virada do milênio, tudo foi se transformando com uma rapidez que já não somos capazes de acompanhar: o Facebook, o e-mail, o fone de ouvido e o smartphone já não são meros intermediários que facilitam a comunicação; tornaramse fins em si mesmos e passaram a nos dominar. ${ }^{2}$ Cada um fechou-se em si mesmo, passando a interessar-se mais por um mundo virtual que pela realidade propriamente dita. Já não conversamos, pois vivemos na ilusão de não precisar uns dos outros. $\mathrm{O}$ excesso de facilidades converteu-se numa dificuldade em si (cf. OLIVEIRA, 2008). 
Deve ser lembrado que nossa espécie, Homo sapiens sapiens, foi a mais bem sucedida dentre vinte espécies humanas. As outras dezenove se extinguiram ao longo dos últimos milhóes de anos. Nossos ancestrais chegaram a conviver com o Homem de Neandertal, que também desapareceu. Se conseguimos sobreviver às dezenas de milênios que marcaram o fim da Idade do Gelo (intervalo que, comparado à idade da Terra, não chega a ser nem um piscar de olhos) e ele não, tudo indica ter sido graças à nossa maior desenvoltura no andar (o neandertalense caminhava arrastando os pés) e no falar: a linguagem mais precisa nos permitia entender melhor os movimentos migratórios dos grandes mamíferos que nos serviam de alimento; um planejamento mais adequado para seguir as mesmas trilhas e uma capacidade locomotora mais desenvolvida fizeram a diferença: enquanto o Homo neanderthalensis desaparecia de cena (seu último registro data de $27 \mathrm{mil}$ anos), o Homo sapiens sapiens sobreviveu ao frio, interessou-se pela beleza, criou a arte rupestre, começou a domesticar animais e inventou a agricultura (cf. SCHRENK \& MÜLLER, 2005). Ora, se a capacidade de nos comunicarmos com maior precisão fez a diferença no que se refere à nossa vitória sobre as grandes intempéries naturais dos últimos milênios, não será o declínio dessa mesma faculdade um sinal preocupante para nós? Neste mundo em que todos os nossos sentidos são incessantemente bombardeados por mensagens (a maioria delas prejudiciais ou simplesmente inúteis), sobra cada vez menos tempo para a meditaçáo, o silêncio e o conhecimento de nós mesmos - que sempre foi, é e será o mais importante de todos os alvos a conhecer (cf. MEISTER ECKHART, 2006). Como ficará a situação do cego e demais deficientes num mundo cada vez mais descrente de valores espirituais e, consequentemente, mais materialista, egoísta e amoral?

É lamentável ver um naturalista de valor como o britânico David Attenborough (1926) negar o papel de Deus como Criador da vida e do próprio Universo, baseado no fato de a natureza estar repleta de ameaças e males diversos. No seu entender, "se Deus existisse e fosse bom", não teria criado o verme Onchocerca volvulus, responsável pela oncocercose, doença endêmica na África (99\% dos 18 milhóes de infectados no mundo são africanos), que costuma causar a cegueira (cf. IGREJA et al., 2001). Sim, o mal existe na natureza, na vida e em tudo o que nos rodeia. Não sabemos explicar cientificamente sua origem, suas causas e seus propósitos. Justamente por não o compreendermos mediante a ciência, não estamos autorizados a usá-lo como argumento científico - mas é isso o que sir David Attenborough faz para justificar seu agnosticismo. Nada impede, inclusive, que aquilo que nós chamamos de mal seja, num plano mais amplo, um bem. Quem tiver dúvidas sobre isso, que assista ao programa radiofônico $O$ que os olhos não vêem, de Frei Anselmo Fracasso, ele mesmo cego (devido à ação nociva de uma bactéria) e plenamente realizado como pessoa, apesar da cegueira. Santo Agostinho (354-430), que era africano (pelas fronteiras atuais, diríamos argelino) e, tal como Frei Anselmo, padeceu sofrimentos que Attenborough certamente desconhece, é partidário daquela mesma opinião (a de que o que nós chamamos de mal pode ser um bem, considerando os desígnios divinos, tantas vezes insondáveis para o nosso entendimento), defendida com maestria no diálogo De ordine, uma das obras que lhe fizeram dele o autor mais influente de toda a cultura ocidental (FRANZEL, 1974). Se hoje em dia ele é praticamente desco- 
nhecido no Magreb em que nasceu, podemos considerar suas palavras como aquelas sementes que caíram sobre as pedras e "secaram por falta de umidade"; ou então no meio de espinhos "que, ao crescerem com elas, sufocaram-nas" (Lc 8:5-8).

Há cerca de cinquenta anos, o pintor austríaco Oskar Kokoschka legou à posteridade uma grave advertência:

Tento ensinar meus alunos [de pintura] a ver. (...) Na minha juventude poucas pessoas podiam se dar ao luxo de viajar. Mas os viajantes, que levavam consigo um caderno de desenho nas férias, eram proporcionalmente tão numerosos como os que hoje levam consigo um aparelho fotográfico. As pessoas que desenhavam, estas não se arrogavam o direito de serem artistas, e tampouco nutriam ilusôes quanto a terem talento. Ao contrário: desenhar incluía-se nos divertimentos das férias, era um meio de enobrecer o que se via, de recolhê-lo em si. Eu tenho a impressão de que são muitos os turistas de hoje que, inseparáveis da sua câmera, tornaram-se cegos, se não corporalmente, ao menos espiritualmente; melhor dizendo: seus olhos já não funcionam mais como órgãos humanos, mas sim como um tipo de acessório da sua câmera. (apud RODITI, 1973).

Os viajantes de hoje não desenham mais, porque desenhar exige o esforço do aprendizado, coisa impopular num mundo em que tudo se tornou "fácil". Renunciando ao desenho, renunciamos também ao uso de partes fundamentais do nosso cérebro, inatividade que provocará a sua inevitável atrofia. Não estamos longe do tempo em que o confronto com o "difícil" será interpretado pelo cérebro humano como o descarrilar de um trem (cf. EDWARDS, 2013). Prova disso temos na maior parte do que se convencionou chamar de "arte contemporânea", retrato de uma época medíocre e arrogante, na qual poucos querem aprender o que não sabem e muitos se consideram gênios sem saber os princípios básicos do ofício que escolheram.

Confirmando a regra apontada pelo economista e banqueiro Muhammad Yunus relativa aos países pobres (nestes, as empresas funcionam melhor sob a direção das mulheres), eis um exemplo edificante que nos vem da Namíbia, mais precisamente de Martha Muulyau e outras mulheres namibianas da associação Penduka, graças à qual elas, também paralíticas, obtêm seu sustento mediante a venda de bordados e outros produtos artesanais. Fundada por Martha e pela holandesa Christien Roos, "penduka", nas línguas oshiwambo e otjiherero não poderia significar algo mais apropriado: "desperta!" - exclamação que lembra a que fez Jesus ao deficiente do Evangelho: "levanta-te e anda" (Mc 2, 9-10).

\section{Referências}

BERTAUX, P. África. Desde la prehistoria hasta los años sesenta (trad. Manuel Ramón Alarcón), México/ Buenos Aires/Madrid: Siglo Ventiuno, 1994.

CARROUGES, M. Charles de Foucauld, explorateur mystique, Paris: Ed. du Cerf, 1954.

DRÖSCHER, V. B. ...und der Wal schleuderte Jona an Land: die Tierwunder der Bibel naturwissenschaftlich erklärt, Hamburgo: Goldmann, 1987.

EDWARDS, B. Drawing on the Right Side of the Brain, 4. ed., Londres: Souvenir Press, 2013. 
EMMOTT, S. 10 Billion. Londres: Penguin Books, 2013.

FRANZEL, E. Geschichte des deutschen Volkes. Munique: Adam Kraft, 1974.

GRIMBERG, C. História da civilizaçáo (trad. Jorge de Macedo). Lisboa: Europa-América, 1965.

IGREJA, R. P. et al. Medicina tropical. Abordagem atual das doenças infecciosas e parasitárias. Rio de Janeiro: Cultura Médica, 2001.

JAUD, L. L. Vies des Saints. Paris: Tours Maison Mame, 1933.

MEISTER EKHART. Eins werden (ed. por Gudrun Griesmayr). Viena: Neue Stadt, 2006.

NARLOCH, L. Guia politicamente incorreto da história do Brasil. 2. ed., São Paulo: Leya, 2011.

NIETZSCHE, F. Wille zur Macht. Stuttgart: Kröner, 1952.

OLIVEIRA, J. V. G. Estética, vivência humana. Rio de Janeiro: Letra Capital, 2008.

PENNA, J. O. de. M. O espírito das revoluçóes. Rio de Janeiro: Faculdade da Cidade, 1997.

ROUSSEAU, J. J. Emílio (trad. Sérgio Milliet). 3. ed., São Paulo/Rio de Janeiro: Difel, 1979.

SAUCH, X. M. El sentit d'una vida: un monjo atípic. Barcelona: Publicacions de l'Abadia de Montserrat, 2007.

SCHRENCK, F; MÜLLER, S. Die Neandertaler. Munique: C. H. Beck, 2005.

SPIEGEL, P. Muhammad Yunus, o banqueiro dos pobres (trad. Siomara Fernandes Costa). São Paulo: Cidade Nova, 2009

TISSOT, Y. "Un médicin de La Côte construit un hôpital en Côte d'Ivoire", in Tribune de Génève, 21/02/2001.

ZAPPA, C. "A caça aos negros brancos”. In: Mundo e missão, São Paulo: ago. 2010, n. 144.

\section{Notas}

${ }^{1}$ Muito adequado foi o título Out of Africa dado ao filme dirigido por Sydney Pollack em 1985, e estrelado por Meryl Streep e Robert Redford. Baseada no livro autobiográfico Den afrikanske Farm ("A fazenda africana"), da dinamarquesa Isak Dinesen (pseudônimo de Karen Blixen), esta obra-prima do cinema teve o título mal traduzido no Brasil por "Entre dois amores" <cf. http://pt.wikipedia.org/wiki/Out_of_Africa>. Acesso em: mai. 2014

${ }^{2} \mathrm{O}$ vício "em internet" já é reconhecido oficialmente como doença <cf. http://www.estadao.com.br/noticias/cidades, mulher-se-interna-em-clinica-para-tratar-vicio-de-internet,1125287,0.htm>. Acesso em: abr. 2014.

\section{Correspondência}

João Vicente Ganzarolli de Oliveira - Rua Pio Correa n. 98/303, CEP: 22461-240, Rio de Janeiro, Rio de Janeiro - Brasil.

E-mail: jganzarolli@usa.com

Recebido em 03 de setembro de 2014

Aprovado em 22 de outubro de 2014 